\title{
Paired records of global weathering and redox across the Ediacaran- Cambrian Boundary
}

\author{
ROSALIE TOSTEVIN ${ }^{1}$, MCDONALD T MTONDA ${ }^{1}$, \\ MAPASEKA MASHEGO ${ }^{1}$, WENDY L. TAYLOR ${ }^{1}$, PETRUS \\ LE ROUX ${ }^{1}$ AND MORTEN B ANDERSEN ${ }^{2}$ \\ ${ }^{1}$ University of Cape Town \\ ${ }^{2}$ Cardiff University
}

Presenting Author: rosalie.tostevin@uct.ac.za

The Late Ediacaran to early Cambrian is a key interval in the transition towards a metazoan-dominated biosphere. The Nama Assemblage of the Ediacaran biota, which includes the earliest skeletal metazoans, is recorded within the Nama Group in South Africa and Namibia. Cambrian-type fauna including bilaterian trace fossils appear towards the top of the Nama Group. These biotic events are recorded within or closely interbedded with carbonate rocks that record aspects of coeval seawater chemistry. We present $\mathrm{Ce}$ anomaly data that constrain local redox conditions during deposition. These data are tied to palaeontological logs, allowing us to assess the influence of oxygen levels on the distribution of biota. In addition, we present new ${ }^{238} \mathrm{U}$ data that constrain the global extent of anoxia across the Ediacaran-Cambrian Boundary. These data provide insight into the role of global environmental change, if any, on faunal turnover. These redox proxies are tied to new high-resolution ${ }^{87} \mathrm{Sr} /{ }^{86} \mathrm{Sr}$ data for the Nama Group, which capture some of the highest values in Earth history, to understand interactions between long timescale re-organisation of continents and the geochemical and biotic response. 